\title{
A ESCOLARIZAÇÃO DOS DESCENDENTES DE JAPONESES NO BRASIL: PONTOS PARA UMA REFLEXÃO
}

(Resumo da tese de doutorado em Educação apresentada sob orientação do prof. Dr. José Augusto da Silva Pontes Neto à Faculdade de Filosofia e Ciências de Marília, Universidade Estadual Paulista "Júlio de Mesquita Filho, 1999, 217p.)

Ruth Izumi Setoguti*

Procurou-se, nesta pesquisa, investigar, através do método da história, os fatores subjacentes ao sucesso escolar dos descendentes de japoneses no Brasil. A hipótese é que as pessoas desse grupo étnico trazem como herança cultural, em razão de fatores de ordem histórica, um forte sentimento de valorização da educação, que as impulsiona para o êxito escolar. Recorreu-se a pesquisa de fontes bibliográficas e a trabalho de campo. O objetivo era não só descobrir as causas do sucesso escolar dos nipo-brasileiros como também fornecer outros elementos para o debate acerca do fracasso escolar, tomando como parâmetro outro lado do fenômeno: o sucesso escolar. Os resultados da pesquisa apontam para o fato de que, na base do sucesso escolar dos descendentes de japoneses esta o papel imprescindível da família.

Palavras-chave: herança cultural, japoneses, educação.

* Professora adjunta do Departamento de Teoria e Prática da Educação da Universidade Estadual de Maringá. Endereço para correspondência: Departamento de Teoria e Prática da Educação da Universidade Estadual de Maringá, Av. Colombo, 5790, CEP 87020-900, Maringá, Paraná.

\begin{tabular}{|l|l|l|l|l|l|}
\hline Psicologia em Estudo & DP/CCH/UEM & v. 5 & n. 1 & p. 149 & 2000 \\
\hline
\end{tabular}

